\title{
Direct measurements of biogenic dimethylsulphide fluxes from the oceans: a synthesis ${ }^{1}$
}

\author{
H.J. Zemmelink, J.W.H. Dacey, and E.J. Hintsa
}

\begin{abstract}
This paper provides a brief overview of the state-of-the-art of techniques that are currently used for field measurements of trace gas fluxes and the subsequent derivation of gas transfer rates over the oceans. Special attention is given to the relaxed eddy accumulation (REA) and gradient flux (GF) techniques, which rely on empirical functions thus far mainly validated over land. The universality of these functions and their application at sea have not yet been fully evaluated. New experiments have shown that the emission of dimethylsulphide (DMS) can be measured by the REA and GF techniques. Moreover, these measurements have provided parameterizations of gas exchange rates that are within the range of relationships between wind speed and gas transfer that have recently been derived from eddy correlation (EC) and deliberate tracer measurements. Using DMS as a model, gas is potentially a powerful approach to intercalibrate the REA, GF, and EC techniques, test their applicability in the marine environment, and investigate processes that determine trace gas exchange across the ocean surface.
\end{abstract}

Résumé : Nous présentons ici une courte synthèse des meilleures techniques courantes utilisées pour mesurer en nature les flux de gaz en traces et pour ensuite dériver les taux de transferts des gaz au-dessus des océans. Il est particulièrement question des techniques REA («Relaxed Eddy Accumulation », méthode simplifiée d'accumulation des tourbillons) et GF («Gradient Flux », méthode de gradient des flux) qui reposent sur des fonctions empiriques validées jusqu'à maintenant surtout sur le continent. L'universalité de ces fonctions et leur application à l'environnement marin n'ont pas encore été complètement évaluées. De nouvelles expériences indiquent que l'émission de sulfure de diméthyle (DMS) peut être mesurée par les techniques REA et GF. De plus, ces mesures ont fourni des paramètres pour les taux d'échanges gazeux qui se situent dans la gamme des relations entre la vitesse du vent et le transfert des gaz obtenues récemment par la méthode EC («Eddy Correlation », méthode des corrélations turbulentes) et par des additions délibérées de traceurs (« deliberate tracer method»). L'utilisation du DMS comme gaz modèle pourrait permettre de calibrer les méthodes REA, GF et EC entre elles, de vérifier leur applicabilité au milieu marin et d'étudier les processus qui déterminent les échanges de gaz en traces de part et d'autre de la surface des océans.

[Traduit par la Rédaction]

\section{Introduction}

Ocean-atmosphere interactions and feedback mechanisms are key processes that need to be quantified to understand the role of the oceans in atmospheric chemistry and global climate. The biogenic gas dimethylsulphide (DMS) and its precursor dimethylsulphoniopropionate (DMSP) are at the center of attention of international research programs such as SOLAS (Surface Ocean - Lower Atmosphere Study) because of the potential of DMS to regulate climate. Since
Lovelock et al. (1972) reported that DMS emissions from the oceans could possibly close the global sulphur budget, empirical evidence for a DMS-driven negative climate feedback has been found (Ayers and Gillet 2000; Sciare et al. 2000). This supports the suggestion of Charlson et al. (1987) and more recently Andreae and Crutzen (1997) that atmospheric oxidation products of DMS are part of one of the major feedback mechanisms linking the global biosphere and climate, with a possible cooling capacity of about $4{ }^{\circ} \mathrm{C}$ (Watson and Liss 1998).

Received 1 February 2003. Accepted 7 November 2003. Published on the NRC Research Press Web site at http://cjfas.nrc.ca on 24 June 2004.

$\mathrm{J} 17361$

H.J. Zemmelink, ${ }^{2}$ J.W.H. Dacey, and E.J. Hintsa. Woods Hole Oceanographic Institution, Woods Hole, MA 02543, U.S.A.

${ }^{1}$ This paper is part of the proceedings of the Third International Symposium on Biological and Environmental Chemistry of DMS(P) and Related Compounds, held in Rimouski (Québec), 26-28 September 2002.

${ }^{2}$ Corresponding author (e-mail: hzemmelink@whoi.edu). 
Table 1. Parameterizations of gas transfer $(k)$ as a function of wind speed $(U)$ at an elevation of $10 \mathrm{~m}$.

\begin{tabular}{ll}
\hline Parameterization & Equation \\
\hline Liss and Merlivat 1986 & $k=0.17 U\left(U \leq 3.6 \mathrm{~m} \cdot \mathrm{s}^{-1}\right)$ \\
Liss and Merlivat 1986 & $k=2.85 U-9.65\left(3.6<U \leq 13 \mathrm{~m} \cdot \mathrm{s}^{-1}\right)$ \\
Liss and Merlivat 1986 & $k=5.9 U-49.3\left(U>13 \mathrm{~m} \cdot \mathrm{s}^{-1}\right)$ \\
Wanninkhof 1992 & $k=0.39 U^{2}$ (long-term-averaged winds) \\
Wanninkhof 1992 & $k=0.31 U^{2}$ (short-term-averaged winds) \\
McGillis et al. 2001a & $k=3.3+0.026 U^{3}$ \\
Nightingale et al. 2000 & $k_{600}=0.33 U+0.222 U^{2}, R^{2}=0.80$ \\
Jacobs et al. 1999 & $k=(0.54 \pm 0.08) U^{2}, R^{2}=0.17$ \\
Hintsa et al. 2004 (FAIRS-GF) & $k=(0.18 \pm 0.03) U^{2}, R^{2}=0.18$ \\
Zemmelink et al. 2004a (FAIRS-REA) & $k=(0.61 \pm 0.06) U^{2}, R^{2}=0.36$ \\
Zemmelink et al. 2004b (GasEx-2001-GF) & $k=(0.60 \pm 0.04) U^{2}, R^{2}=0.28$ \\
Zemmelink et al. 2004b (pooled GasEx-FAIRS) & $k=(0.48 \pm 0.09) U^{2}, R^{2}=0.31$ \\
\hline
\end{tabular}

Note: Gas transfer rates or velocities are normalized to a Schmidt number of 660 .

DMS and its oxidation products affect atmospheric chemistry in various ways (Andreae and Crutzen 1997). Once emitted from the oceans, DMS is oxidized by free radicals such as $\mathrm{OH}$ and $\mathrm{NO}_{3}$ to form a variety of products including methane sulphonic acid and sulphur dioxide, part of which in turn are oxidized to form non-sea-salt sulphate (NSS sulphate). Even with an understanding of the dynamics of DMS in the atmosphere, current models are still unable to simulate the oceanic climate feedback system. The uncertainty of the atmospheric burden is at least equal to the uncertainty in the magnitude of the sea to air fluxes. The most recent estimates of the sea to air flux of DMS range from 15 to $33 \mathrm{Tg} \mathrm{S} \cdot \mathrm{year}^{-1}$ (Kettle and Andreae 2000), a significant contribution to the global atmospheric sulphur burden and the dominant one over large regions of the oceans. Gondwe et al. (2003) recently estimated the average contribution of DMS to the overall atmospheric sulphur burden at $18 \%$, but this percentage varies greatly: $43 \%$ in the relative pristine Southern Hemisphere and 9\% in the Northern Hemisphere because of the dominance of sulphur from fossil fuel burning.

Commonly used gas exchange models rely on the assumption that the flux $(F)$ of a gas across the air-water interface is the product of the air-water concentration disequilibrium $(\Delta C)$ and a kinetic parameter, the transfer velocity $\left(k_{\mathrm{gas}}\right)$, which quantifies the rate at which the gas crosses the air-sea interface:

$$
F=k_{\text {gas }} \Delta C
$$

The air-water disequilibrium for most volatile compounds is highly variable because it is a function of time, location, meteorological conditions, and chemical/biological processes. Even when spatial and seasonal surface water concentrations are fairly well known, it remains difficult to calculate fluxes because the rate of transfer across the water surface is uncertain (Wanninkhof 1992). Although parameterizations of $k_{\text {gas }}$ as a function of wind speed are available (Liss and Merlivat 1986; Wanninkhof 1992; Erickson 1993), the fundamental physical nature of $k_{\text {gas }}$ remains poorly understood and it is usually parameterized as the waterside transfer velocity $\left(k_{\mathrm{w}}\right)$ as a function of wind speed $(U)$ and temperature in the form

$$
k_{\mathrm{w}} \approx a U^{x} \mathrm{Sc}^{n}
$$

where Sc is the dimensionless Schmidt number: the ratio of the kinematic viscosity of water ( $\mathrm{v}$, metres per second squared) and the molecular diffusivity of the gas $(D$, metres per second squared), $\mathrm{Sc}=\mathrm{v} / D$. Molecular diffusivities have been quantified for a range of gases (e.g., Jähne et al. 1987; Wanninkhof 1992; Saltzman et al. 1993) and the kinematic viscosity of seawater is well known. The Sc exponent, $n$, is a function of surface characteristics and has been determined to be $-2 / 3$ for smooth water surfaces (wind speed $\leq 3.6 \mathrm{~m} \cdot \mathrm{s}^{-1}$ ) and $-1 / 2$ for rough surfaces (wind speed $>3.6 \mathrm{~m} \cdot \mathrm{s}^{-1}$ ). The wind speed exponent $(x)$ expresses the wind speed dependency of $k$. Estimates of $x$ range from linear (Liss and Merlivat 1986) to cubic (Wanninkhof and McGillis 1999). The regression coefficient $a$ is derived from the best fit through observed values of $k$. Estimates of the regression coefficient vary from a factor of 2 between the most commonly applied parameterizations of Liss and Merlivat (1986) and Wanninkhof (1992) to a factor of 3 between parameterizations that are based on the direct measurement of $k$ in the field (Table 1).

Usually, transfer velocities are normalized to the Sc of $\mathrm{CO}_{2}$ in seawater at $20{ }^{\circ} \mathrm{C}$ with a salinity of $35 \%$ o $(\mathrm{Sc}=660)$ by means of the $\mathrm{Sc}$ dependence

$$
k_{660}=k_{\mathrm{w}}(660 / \mathrm{Sc})^{n}
$$

Extrapolating measured fluxes of one gas to estimate fluxes of other gases requires conversion through the Sc using $k_{\text {gas A }}=k_{\text {gas B }}\left(\mathrm{Sc}_{\text {gas A }} / \mathrm{Sc}_{\text {gas B }}\right)^{n}$. However, the power dependence of Sc changes under wave-breaking conditions where poorly soluble gases are transported relatively more efficiently by bubbles than more soluble gases (Woolf 1993). Hence, Sc conversions are valid only as long as $k$ remains independent of the gas solubility (Asher and Wanninkhof $1998 a$ ). The effect of bubbles on air-sea gas exchange is a topic of ongoing research and still far from resolution (Donelan et al. 2002 and references therein). In addition, the solubility and aqueous reactivity of a gas determine whether gas transfer will be limited by the waterside or airside. For gases with low solubility, the gas transfer is predominantly controlled by the liquid phase. The exchange of gases with high solubilities is limited by transfer through the airside. Gases that have an intermediate solubility, such as DMS, 
will experience part liquid and part airside control, and the predominance will depend on turbulence and the temperature dependence of the gas solubility (McGillis et al. 2000). A correction should be applied for the airside control of moderately soluble gases if gas exchange rates are expressed in terms of $k_{660}$ (the waterside controlled transfer velocity of $\mathrm{CO}_{2}$ ).

The two most commonly applied gas exchange parameterizations have been developed by Liss and Merlivat (1986) and Wanninkhof (1992). That of Liss and Merlivat (1986) was deduced from a deliberate tracer experiment with sulphur hexafluoride $\left(\mathrm{SF}_{6}\right)$ in a lake for wind speeds up to $8 \mathrm{~m} \cdot \mathrm{s}^{-1}$ and from wind tunnel data at higher wind speeds. That of Wanninkhof (1992) is a quadratic fit in agreement with the global mean transfer velocity determined from the oceanic uptake of bomb-derived radiocarbon. Purposefully released tracers have been used more recently in oceanic settings (Asher and Wanninkhof 1998a, 1998b; Nightingale et al. 2000). These bulk parameterizations have the drawback that they yield relationships averaged over longer time intervals and over larger spatial scales for oceanic conditions that may be hard to characterize because of their variability. In other words, these parameterizations do not provide adequate insight into the temporal and spatial variability of $k$.

Direct determination of $k$ in the field would clearly be preferable but has proven to be difficult. A number of techniques have been developed in recent years (reviewed by Asher and Wanninkhof 1998a; Fairall et al. 2000). Examples of techniques in the aqueous phase are the dissolved gas balance technique (Wallace and Wirick 1992; Farmer et al. 1993) and the controlled flux method (Jähne et al. 1989; Haußecker et al. 1995). Both of these are used to determine the change of a quantity (the concentration of a gas or heat, respectively) over time. Although these techniques provide insight into physical processes that control gas transfer and give a direct estimate of the budget of the measured tracer, conversion to gas transfer rates of other gases using eq. 3 might still be unreliable because of the effect of breaking waves (and solubility). A major disadvantage of the controlled flux method lies in its inability to measure the bubblemediated component. In contrast, micrometeorological techniques in the airside allow the field measurement of fluxes and the derivation of transfer velocities without recourse to other gases, on time scales of less than an hour for most sea states. These techniques link atmospheric turbulence, generated by the friction between air and the sea surface and by density variations (buoyancy) in the atmosphere (determining atmospheric stability), to gas exchange. Several micrometeorological techniques have been applied for the measurement of turbulence and gas fluxes at sea, among which are the eddy correlation, relaxed eddy accumulation, and profiling techniques.

\section{Micrometeorological techniques used for field estimates of gas transfer}

\section{Eddy correlation}

Eddy correlation (EC) is the most straightforward and basic approach for flux measurement, where the flux (moles per square metre per second) is obtained from the product of concurrent instantaneous measurements of the fluctuations of vertical velocity $w^{\prime}$ (metres per second) and gas concentration or mixing ratio $\chi_{c}^{\prime}$ (moles of gas per mole of air):

$$
F_{\mathrm{c}}=\rho_{\mathrm{a}}\left(\overline{w^{\prime} \chi_{\mathrm{c}}^{\prime}}\right)
$$

where $\rho_{a}$ (moles per cubic metre) is the density of dry air and the overbar denotes a time average. EC gives an unambiguous result for the absolute flux but requires instruments that are capable of high-resolution measurements of both air motion and air composition at frequencies of approximately $10 \mathrm{~Hz}$. This is easily achieved for fast-response air motion sensors such as sonic anemometers, but the availability of suitable trace gas sensors, often infrared absorption devices, is limited to gases such as $\mathrm{O}_{3}, \mathrm{SO}_{2}, \mathrm{NO}, \mathrm{NO}_{2}, \mathrm{CH}_{4}$, and $\mathrm{CO}_{2}$.

Unfortunately, trace gas fluxes over the ocean are often at the limit of detection of fast-response sensors, thus hampering the applicability of EC in the marine environment. Another method to estimate the absolute flux was proposed by Desjardins (1977), who suggested a variant of EC that does not rely on fast-response gas sensors. This technique is known as eddy accumulation in which air is drawn from the immediate vicinity of an anemometer measuring vertical wind speed $(w)$ and subsequently diverted into one of two accumulators on the basis of the sign of $w$ at a pumping rate proportional to the magnitude of $w$. Sampling air at a rate proportional to the vertical wind velocity is, however, extremely difficult to achieve in real time. Other techniques of measuring fluxes generally require some empirically determined relationship to estimate the flux. Two such methods are the relaxed eddy accumulation (REA) and the profiling or gradient flux (GF) techniques, which allow the storage of gases and later analysis.

\section{Relaxed eddy accumulation}

Businger and Oncley (1990) examined sets of raw EC measurements of vertical wind speed, humidity, and temperature and noted that if measurements of temperature and humidity were segregated according to the sign of the vertical wind speed, then the flux was proportional to the product of the standard deviation of the vertical wind speed, $\sigma_{\mathrm{w}}$ (metres per second), and the difference between the two samples:

$$
F_{\mathrm{c}}=\beta \sigma_{\mathrm{w}}\left(\bar{C}_{\mathrm{u}}-\bar{C}_{\mathrm{d}}\right)
$$

where $\beta$ is the eddy accumulation coefficient (dimensionless) and $\bar{C}$ is the mean concentration (moles per cubic metre) in the upward- and downward-moving eddies. This observation allows for the application of the REA method, which is based on sampling air into updraft and downdraft reservoirs at a constant flow rate rather than proportionally to the vertical wind speed, $w$, as in the case of true eddy accumulation. For a Gaussian distribution, the $\beta$ factor is a constant $(0.627$; Wyngaard and Moeng 1992). However, several field experiments yielded $\beta$ values that were on average between 0.56 and 0.60 (Businger and Oncley 1990; Baker et al. 1992; Pattey et al. 1993), sometimes showing considerable scatter with ranges from 0.2 to 0.9 (e.g., Oncley et al. 1993; Beverland et al. 1996). It is still uncertain whether $\beta$ is absolutely constant or varies systematically, depending on the relative contribution of buoyancy and friction to turbulence. Businger and Oncley (1990) and more recently Andreas et 
al. (1998) proposed $\beta$ as a general function of stability $(z / L$, where $z$ is the measurement height (metres) and $L$ is the Obukhov length (metres), which reflects the relative contribution of buoyancy and friction to the production of turbulence). However, only a weak systematic variation was detected and could not be reproduced by other authors (e.g., Beverland et al. 1996). Most studies use a constant literature value for $\beta$ between 0.56 and 0.60 or derive $\beta$ from EC measurements.

Often, a sampling threshold around zero (metres per second) vertical wind speed is used, where neither updraft nor downdraft air is sampled. This deadband approach has the advantage of increasing the concentration difference between the two collection reservoirs because sampling is biased toward larger eddies (those with sufficient vertical velocity to exceed the threshold), which tend to move farther along the concentration gradient. The quantitative effect of the deadband on the REA measurements is still a matter of investigation. However, it is generally accepted that the increase in concentration difference must be balanced by a decrease in $\beta$. The correction for the increased concentration difference was evaluated by Businger and Oncley (1990) and more recently by Pattey et al. (1993). Both studies found an exponential decrease in $\beta$ with increasing deadband. Businger and Oncley (1990) proposed

$$
\beta=\beta_{0} \exp \left(-0.75 w_{0} / \sigma_{\mathrm{w}}\right)
$$

where $w_{0}$ (metres per second) is the deadband vertical wind velocity threshold for REA measurements. When $w$ is within $\pm w_{0}$, air is discarded. Businger and Oncley (1990) found that $\beta_{0}$ was insensitive to atmospheric stability.

\section{Gradient flux}

With the GF technique (Businger et al. 1971) the flux is derived from the difference in concentration between two or more elevations using Monin-Obukhov similarity theory (the MOST theory states that turbulent statistics are universal functions of $z / L$ when normalized by the appropriate scaling parameter (Monin and Obukhov 1954)

$$
C(z)-C\left(z_{0}\right)=\frac{C_{*}}{k}\left(\ln \left(z / z_{0}\right)-\Psi(z / L)+\Psi\left(z_{0} / L\right)\right)
$$

where $C(z)$ (moles per cubic metre) is the concentration at height $z$ (metres), $\Psi$ (dimensionless) is the integrated flux profile function that corrects for atmospheric stability (Paulson 1970), $k$ is the von Karman constant (0.4), $z_{0}$ is a reference height, and $L$ (metres) is the Obukhov length:

$$
L=\frac{\bar{\theta} u_{*}^{3}}{k g F_{\theta}}
$$

where $\theta$ is the virtual temperature (overbar denotes an average), $u_{*}$ (metres per second) is the friction velocity, which can be derived from EC measurements of wind speed, $g$ is the acceleration due to gravity, and $F_{\theta}$ is the buoyancy flux (derived from EC measurements). The $C_{*}$ (eq. 7) is determined from the least-squares-fitted slope of $C(\mathrm{z})$ as a function of $(\ln (z)-\Psi(z / L))$, the stability-corrected height. The flux is then calculated from

$$
F_{\mathrm{c}}=C_{*} u_{*}
$$

Although EC, REA, and GF techniques have been used extensively over terrestrial systems, their application to air-sea gas exchange is relatively new and there has been an intense effort in the last decade to improve these techniques and to evaluate their accuracy and applicability in the marine environment (Fairall et al. 2000). Specific problems in the marine environment are platform motion, flow distortion caused by the sampling platform, and environmental factors unique to the ocean such as atmosphere-wave interactions.

Generally, EC and wind speed measurements (e.g., of $F_{\theta}$, $u_{*}$, and $\sigma_{\mathrm{w}}$ ) are considered to be accurate, usually within $10 \%$. The accuracy of the EC method is due to the fact that all corrections and flux calculations can be carried out in postprocessing procedures after the field measurements; needless to say, this advantage is also highly appropriate for measurements over sea.

The applicability and performance of the GF method are not only determined by the accuracy of EC but also by the choice of the appropriate measurement heights. The vertical distance should be large enough that it allows concentration differences that are resolvable by available sensors. But the concentrations should also yield a log-linear profile that is, unfortunately, easily disturbed by factors such as flow distortion or waves. The deformation of the log-linear profile is difficult to predict and depends on (wind and wave) conditions during the measurement. In addition, the applicability of Monin-Obukhov similarity theory, the basis of the GF technique, appears to be valid where the generation of turbulence is dominated by friction between the surface and the wind (Edson and Fairall 1998; Edson et al. 2002) but can be questioned over mature seas and swell when turbulence has a strong dependency on waves.

Although EC and wind speed measurements can be corrected for systematic error effects such as an offset in the vertical wind speed and a vertical tilt of the wind sensor, REA measurements cannot be corrected for such errors. This is due to the fact that REA depends on an instantaneous reaction of the sampling system to changes in wind speed. Offset and tilt typically introduce flux errors on the order of 10-20\%. An additional systematic error is caused by the delay time between the wind measurement and the reaction of valves in the sampling system that control the distribution of samples over the appropriate down- or updraft collection reservoir. A mismatch between the wind measurement and the distribution of the samples can result in an underestimation of the flux. However, the use of valves that can respond with a frequency of $20-50 \mathrm{~Hz}$ will minimize the delay and allows measurements with a (delay introduced) error of about $10 \%$. Recent tests of the universality of the empirical functions for REA showed that $\beta$ in the marine environment is indeed not dependent on atmospheric stability and varies around 0.56 (Zemmelink et al. 2004a), in agreement with observations made over terrestrial systems that yield numbers in the vicinity of $0.56-0.58$ (Andreas et al. 1998).

\section{Field estimates of gas transfer rates}

From recent experiments involving field measurement of gas fluxes by a variety of micrometeorological techniques, organized by the U.S. (GasEx-1998, FAIRS, GasEx-2001) and the European Union (ASGAMAGE), a number of rela- 
Fig. 1. Summary of proposed short-term relationships between gas transfer velocities $\left(k_{660}\right)$ and wind speed $\left(U_{10, \mathrm{n}}\right.$, measured at an elevation of $10 \mathrm{~m}$ during neutral conditions). Equations are given in Table 1 . Abbreviations refer to the gases that were measured $\left(\mathrm{CO}_{2}\right.$, carbon dioxide; DMS, dimethylsulphide) and the micrometeorological technique used (EC, eddy correlation; GF, gradient flux; REA, relaxed eddy accumulation; DT, deliberate tracer.

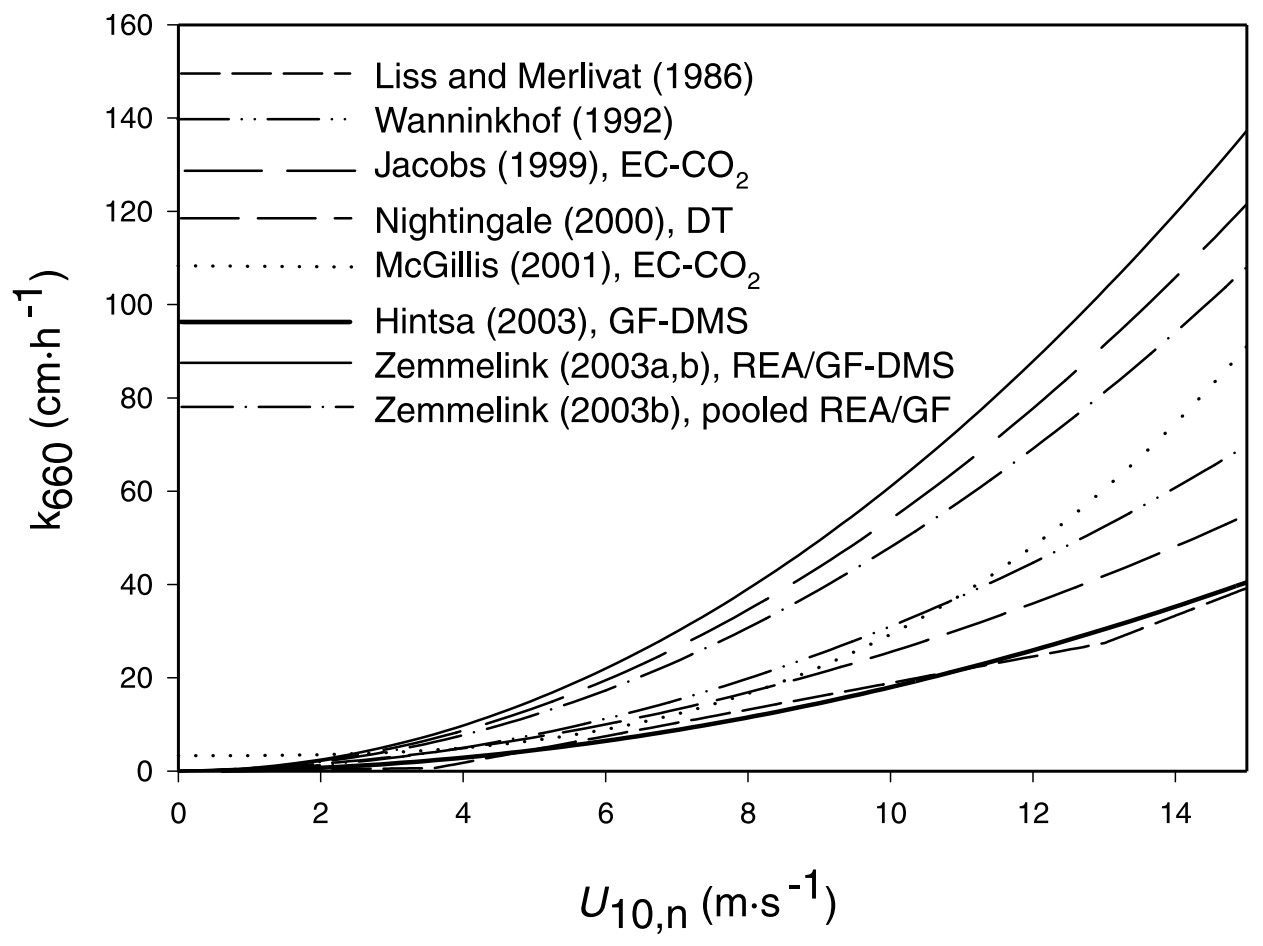

tionships between gas transfer and wind velocities have been proposed (Table 1). These parameterizations relate $k_{\mathrm{w}}$ to short-term measurements of wind speed. This is an important distinction because owing to the nonlinear dependence of gas exchange on wind speed, $k$ estimated over long time periods with variable winds will necessarily be somewhat higher than corresponding estimates over short time scales with more steady winds (for the same average wind speed; Wanninkhof 1992).

Most parameterizations incorporate a nonlinear relationship between gas transfer and wind speed. For example, a cubic dependence between $k$ and wind speed was derived from EC measurements of $\mathrm{CO}_{2}$ flux conducted during GasEx-1998. The cubic dependency incorporates the retardation of gas transfer at low to intermediate winds by surfactants and bubble-enhanced transfer at higher winds (Wanninkhof and McGillis 1999; McGillis et al. 2001a). It is noteworthy that a quadratic fit through the same data corresponds very closely to the Wanninkhof (1992) relationship (Fig. 1). The GasEx-1998 results obtained by EC were within uncertainty in agreement with gas transfer velocities derived from concomitant gradient measurements of the $\mathrm{CO}_{2}$ and DMS flux and with results derived from $\mathrm{SF}_{6}-{ }^{3} \mathrm{He}$ dual tracer release experiments (McGillis et al. 2001b). A quadratic relation was derived from EC measurements of $\mathrm{CO}_{2}$ flux over a coastal shelf sea conducted during ASGAMAGE (Jacobs et al. 1999). These EC results were on average a factor of 2.5 higher than $k$ derived from a simultaneous deliberate tracer experiment (Nightingale et al. 2000), which showed a wind speed dependence intermediate between the relationships proposed by Liss and Merlivat (1986) and Wanninkhof (1992). Part of the difference between the results from the two methods could be explained by near-surface gradients of the inert tracers that caused an underestimation of $k$ up to $25 \%$ (Jacobs et al. 2002). In addition, a 10\% overestimation of the EC estimates could have been caused by biological activity and river discharge affecting surface water $\mathrm{CO}_{2}$ (Jacobs et al. 2002).

Air-sea exchange coefficients in the upper range of commonly used parameterizations were required to be able to close mass budgets of sulphur cycles over the Pacific Ocean (Yvon et al. 1996; Chin et al. 1998). While the studies of GasEx-1998, Yvon et al. (1996), and Putaud and Nguyen (1996) may have given some insight into the magnitude of $k_{\mathrm{DMS}}$, they did not provide a relationship between $k_{\mathrm{DMS}}$ and $U$ or other mechanisms that control gas exchange. More recent experiments, FAIRS (Fluxes, Air-Sea Interaction, and Remote Sensing conducted in 2000; Jessup et al. 2002) and GasEx-2001, allowed the derivation of a parameterization for $k_{\mathrm{DMS}}$. REA and GF techniques were used during those cruises, thus providing the opportunity to measure fluxes in duplicate and compare the applicability of both techniques in the marine environment.

Transfer velocities for DMS from FAIRS and GasEx-2001 are characterized by a considerable amount of scatter that increases with increasing wind speed to over an order of magnitude (Fig. 2). This is in agreement with the scatter observed in EC and GF measurements of the $\mathrm{CO}_{2}$ flux conducted during ASGAMAGE, GasEx-1998, and GasEx-2001 (Jacobs et al. 1999; McGillis et al. 2001b; Zemmelink et al. 2004b).

The FAIRS gas transfer rates of DMS derived from REA were on average about a factor of 2 higher than estimates derived from GF measurements simultaneously applied during 
Fig. 2. Gas transfer velocities $\left(k_{660}\right)$ as a function of wind speed (measured at an elevation of $10 \mathrm{~m}$ during neutral conditions). All transfer velocities are based on dimethylsulphide (DMS) fluxes. $\square$, derived from relaxed eddy accumulation measurements conducted during FAIRS; $\mathbf{\square}$, derived from gradient flux measurements conducted during FAIRS; $\boldsymbol{\Delta}$, derived from gradient flux measurements conducted during GasEx-2001.

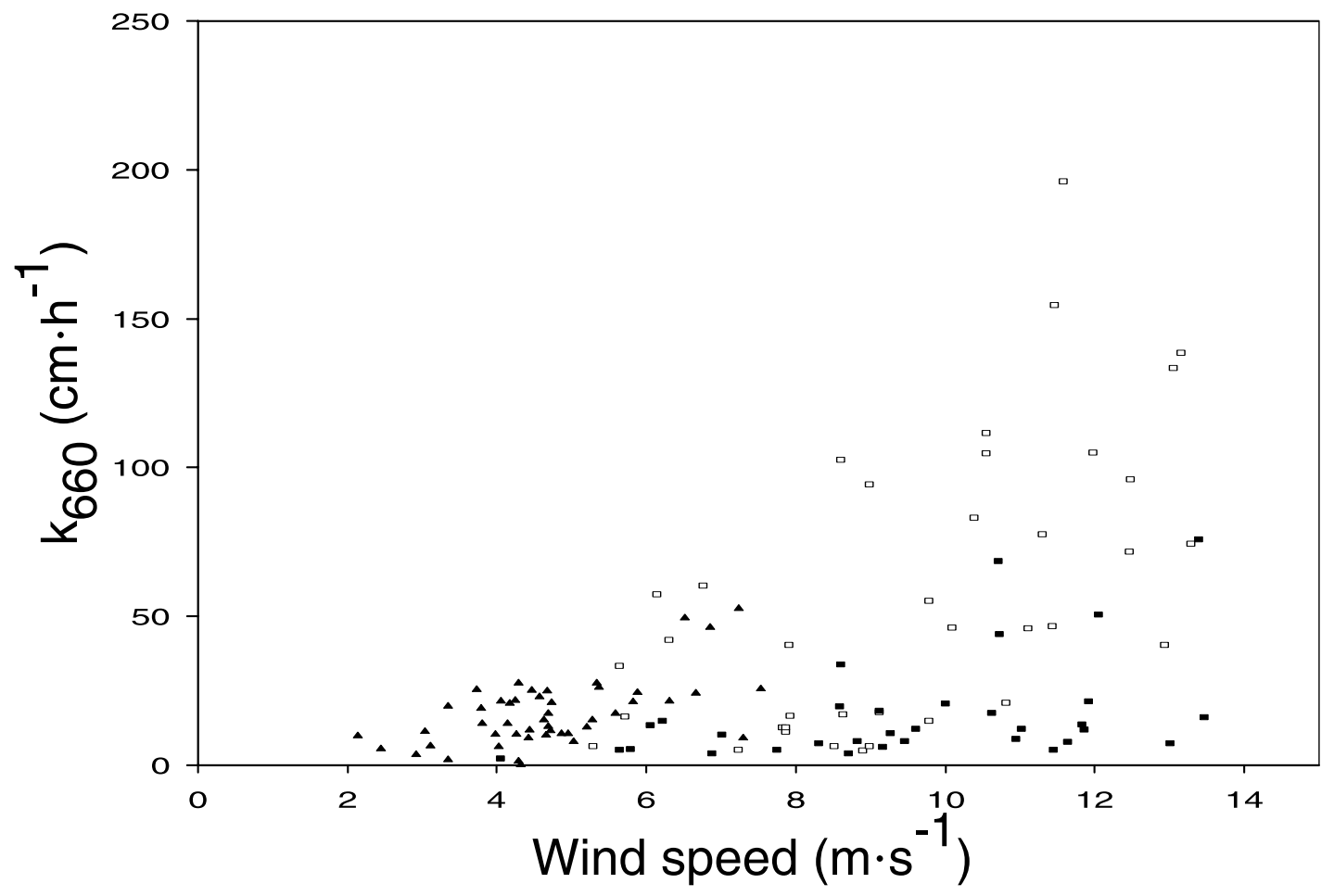

the cruise. No straightforward explanation could be given for the observed discrepancy; however, the effect of sea state and environmental conditions on the measurements is still under consideration. There was no firm rationale to prefer one technique over the other in the marine environment except perhaps that the GF method is less susceptible to ship motion. The GF technique was used for the measurement of DMS fluxes during the GasEx-2001 cruise. Concomitant profile measurements of water vapor fluxes showed that Monin-Obukhov similarity was valid during the meteorological and sea state conditions encountered during the GasEx-2001 cruise (Edson et al. 2002). The relationship between gas transfer and wind speed derived from the GF measurements conducted during GasEx-2001 was very similar to the parameterization derived from REA measurements conducted during FAIRS, and so the data sets were combined to derive a DMS-based gas transfer parameterization for wind speeds between 2 and $13 \mathrm{~m} \cdot \mathrm{s}^{-1}$. The relationship derived from the pooled data set was in close agreement with the parameterization found by Jacobs et al. (1999) from EC $\mathrm{CO}_{2}$ flux measurements. However, the equation derived from the merged FAIRS-GasEx data set was significantly higher than the relationship derived from GF measurements during FAIRS. It was emphasized that there is no reason to assume that either of the two methods used during FAIRS (GF and REA) was erroneous! Moreover, there is no argument to prefer one parameterization over the other. The agreement between the GasEx-GF and FAIRS-REA data sets might have been coincidental. It should be kept in mind that different water characteristics in the two areas, such as the occurrence of surfactants, waves, and swell (FAIRS was conducted at the edge of the California Current and GasEx2001 in the midequatorial Pacific), are likely to have affected gas exchange and the results of the two techniques.

Right now, the influences of surfactants, waves, and swell are not taken into account during the application and interpretation of micrometeorological measurement techniques. In other words, lacking appropriate parameterizations for those influences on the applied techniques, it is not yet possible to ascribe the discrepancies and (or) agreement between techniques and campaigns to well-defined causes.

The parameterizations derived from the field measurements and the commonly applied parameterizations proposed by LM86 and W92 differ by up to a factor of 2-3 (Fig. 1). This is small compared with results obtained with EC techniques during the late 1970s and early 1980s, which showed much larger values of $k$ (Wesely et al. 1982; Broecker et al. 1986; Smith and Jones 1986). These initial experiments have led to technologically improved EC instruments, especially with respect to gas sensors, and to new insights into data quality and the corrections to be applied. Currently, the EC technique may be regarded as a reasonably reliable method for determining $\mathrm{CO}_{2}$ fluxes over the sea. However, all field measurements show a substantial amount of scatter, which results from a combination of effects such as surface and temporal nonhomogeneity, variations in wind speed, and a small signal to noise ratio (some of which are discussed in Jacobs et al. 2002). The conclusion can be drawn that field measurements have not resulted in a convincing parameterization of gas exchange (as a function of wind speed) yet. The scatter in the data suggests that parameterizations based on wind speed alone oversimplify gas exchange and 
do not provide adequate insight into the processes that cause the scatter. Indeed, Bock et al. (1999) emphasized that gas exchange is only indirectly affected by wind speed. Other environmental parameters, such as waves, surface films, and subsurface turbulence, are intermittently linked and influence gas exchange in a more direct manner. Progress in understanding processes that affect gas exchange is most likely to come from a detailed study of the upwind source area of the flux including wind, waves, and surface turbulence. Footprint models allow the determination of this source area and the in situ quantification of parameters that define the magnitude of the flux and will be a valuable addition to future studies of gas exchange.

\section{Recommendations}

Recent experiments have shown that DMS fluxes can be measured by the REA and GF techniques. Moreover, parameterizations of gas exchange rates as a function of wind speed that were derived from these measurements are in reasonable agreement with parameterizations derived from EC and deliberate tracer measurements. Using DMS as a model gas is potentially a powerful tool for future projects that aim at $(i)$ the testing and intercalibration of the REA, GF, and EC techniques in the marine environment, (ii) the investigation of processes that control fluxes, and (iii) the estimation of trace gas budgets on regional to global scales.

In contrast with the EC technique, REA and GF do not measure absolute fluxes, and although models that REA and GF rely on appear to be applicable in the marine environment, further testing under different conditions is needed before we can be fully confident in the application of these techniques. The lack of fast-response DMS sensors has allowed few EC measurements (Mitchell 2001), but new developments in gas analysis using mass spectrometry should make EC feasible for DMS (e.g., Bandy et al. 2002; Spicer et al. 1996). Bypassing the traditional approach for EC (based on continuous high-frequency sampling of air), fluxes can also be calculated from only a subset of the whole time series by taking quick samples at a low frequency (Rinne et al. 2000). Based on this approach, an EC system was developed that makes eddy covariance flux measurements possible using relatively slow sensors such as for methanol (Rinne et al. 2001). At this point, however, the use of micrometeorological techniques for field measurements of the flux of any gas in the marine environment is still in its infancy and intercalibration of techniques is required.

Although micrometeorological methods yield average net fluxes and exchange rates for areas with a length scale of about $10-1000 \mathrm{~m}$ (as a rule of thumb, 100 times the measurement height), they do not provide insight into processes that occur on the much smaller scales where fluxes are truly controlled or at the larger length scales that are needed to study biosphere-climate interactions. In the case of DMS, gas exchange might dominate removal in the upper metre of the water column, while biological consumption seems to be the most important removal pathway when the whole mixed layer is considered (Kieber et al. 1996). The combination of small-scale in situ studies, using, for example, enclosures, and the study of processes that occur in the source area of micrometeorological measurements will provide valuable in- formation on the production and fate of DMS in relation to food web dynamics and environmental conditions. Such combined studies might eventually lead to general, global ecology laws that make it feasible to link near-surface dynamics to (DMS) fluxes.

Upscaling from micrometeorological measurements to regional and global scales is possible with airborne measurements that are able to integrate over surface areas with length scales up to hundreds of kilometres. Estimates of air-sea gas transfer can be made by satellite observations of sea surface roughness and thus coupled to the occurrence of waves (Glover et al. 2001). Still, to convert the surface roughness to gas transfer rates and eventually into fluxes, fundamental knowledge on the relationship between surface roughness and gas transfer is needed in combination with information on chemical and biological processes in the surface ocean that determine gas concentrations and fluxes. In addition, comparison of large-scale measurements with in situ measurements is needed to correctly interpret the obtained data. However, interactions between the different length scales can be complex and nonlinear (Jarvis and McNaughton 1986; Klaassen 1992) and results obtained by different flux measurement techniques operating on different scales might not be directly comparable. This remains to be evaluated in future work at sea.

In conclusion, micrometeorological methods cannot address all scales of interest for air-sea gas exchange processes. But they do provide insight into turbulence and biogeochemical processes that determine gas exchange, atmospheric transport, and subsequently atmospheric chemistry. In addition, eddy correlation, (relaxed) eddy accumulation, and profiling methods are most appropriate for the intensive as well as long-term investigation of net exchange over large regions and hence are valuable tools for nutrient cycle and budget studies.

The biogenic gas DMS can be used to investigate the applicability of EC, REA, and GF systems in the marine environment. Moreover, measurement of DMS fluxes provides an indication of the accuracy of EC, REA, and GF systems for the measurement of fluxes of other trace gases. There can be little doubt that the use of DMS as a model gas will strongly contribute to our current knowledge of the coupling between ocean biogeochemistry and global climate.

\section{References}

Andreae, M.O., and Crutzen, P.J. 1997. Atmospheric aerosols: biogeochemical sources and role in atmospheric chemistry. Science (Wash., D.C.), 276: 1052-1058.

Andreas, E.L., Hill, R.J., Gosz, J.R., Moore, D.I., Otto, W.D., and Sarma, A.D. 1998. Stability dependence of the eddy-accumulation coefficients for momentum and scalars. Boundary Layer Meteorol. 86: 409-420.

Asher, W., and Wanninkhof, R. 1998a. Transient tracers and airsea gas transfer. J. Geophys. Res. 103: 15939 - 15958.

Asher, W.E., and Wanninkhof, R. 1998b. The effect of bubblemediated gas transfer on purposeful dual-gaseous tracer experiments. J. Geophys. Res. 103: 10555 - 10560.

Ayers, G.P., and Gillett, R.W. 2000. DMS and its oxidation products in the remote marine atmosphere: implications for climate and atmospheric chemistry. J. Sea Res. 43: 275-286. 
Baker, J.M., Norman, J.M., and Bland, W.L. 1992. Field-scale application of flux measurement by conditional sampling. Agric. For. Meteor. 62: 31-52.

Bandy, A.R., Thornton, D.C., Tu, F.H., Blomquist, B.W., Nadler, W., Mitchell, G.M., and Lenschow, D.H. 2002. Determination of the vertical flux of dimethyl sulfide by eddy correlation and atmospheric pressure ionization mass spectrometry (APIMS). J. Geophys, Res. 107(D24): 4743 (doi: 10.1029/2002JD002472).

Beverland, I.J., Oneill, D.H., Scott, S.L., and Moncrieff, J.B. 1996. Design, construction and operation of flux measurement systems using the conditional sampling technique. Atmos. Environ. 30: 3209-3220.

Bock, E.J., Hara, T., Frew, N.M., and McGillis, W.R. 1999. Relationship between air-sea gas transfer and short wind waves. J. Geophys. Res. 104: 25821 - 25831.

Broecker, W.S., Ledwell, J.R., Takahashi, T., Weiss, R., Merlivat, L., Memery, L., Peng, T.H., Jähne, B., and Munnich K.O. 1986. Isotopic versus micrometeorological ocean $\mathrm{CO}_{2}$ fluxes: a serious conflict. J. Geophys. Res. 91: 10517 - 10527.

Businger, J.A., and Oncley, S.P. 1990. Flux measurement with conditional sampling. J. Atmos. Ocean. Technol. 7: 349-352.

Businger, J.A., Wyngaard, J.C., Izumi, Y., and Bradley, E.F. 1971. Flux profile relationships in the atmospheric surface layer. J. Atmos. Sci. 28: 181-189.

Charlson, R.J., Lovelock, J.E., Andreae, M.O., and Warren, S.G. 1987. Oceanic phytoplankton, atmospheric sulfur, cloud albedo and climate. Nature (Lond.), 326: 655-661.

Chin, M., Rood, R.B., Allen, D.J., Andreae, M.O., Thompson, A.M., Lin, S.J., Atlas, R.M., and Ardizzone, J.V. 1998. Processes controlling dimethylsulfide over the ocean: case studies using a 3-D model driven by assimilated meteorological fields, J. Geophys. Res. 103: 8341-8353.

Desjardins, R.L. 1977. Energy budget by an eddy correlation method. J. Appl. Meteorol. 16: 248-250.

Donelan, M.A., Drennan, W., Saltzman, E., and Wanninkhof, R. (Editors). 2002. Gas transfer at water surfaces. Geophys. Monogr. Ser. 127.

Edson, J.B., and Fairall, C.W. 1998. Similarity relationships in the marine atmospheric surface layer for terms in the TKE and scalar variance budgets. J. Atmos. Sci. 55: 2311-2328.

Edson, J.B., Zappa, C., and McGillis, W. 2002. Scalar flux profile relationships for water vapor over the open ocean. In Fifteenth Conference on boundary layer and turbulence. Extended abstracts. American Meteorological Society, Boston, Mass.

Erickson, D.J., III. 1993. A stability dependent theory for air-sea gas exchange. J. Geophys. Res. 98: 8471-8488.

Fairall, C.W., Hare, J.E., Edson, J.B., and McGillis, W. 2000. Parameterization and micrometeorological measurement of air-sea gas transfer. Boundary Layer Meteorol. 96: 63-105.

Farmer, D.M., McNeil, C.L., and Johnson, B.D. 1993. Evidence for the importance of bubbles in increasing air-sea gas flux. Nature (Lond.), 361: 620-623.

Glover, D.M., Frew, N.M., McCue, S.J., and Bock, E.J. 2001. A multi-year time series of global gas transfer velocity from the TOPEX dual frequency, normalized radar backscatter algorithm. In Gas transfer at water surfaces. Edited by M.A. Donelan, W. Drennan, E. Saltzman, and R. Wanninkhof. Geophys. Monogr. Ser. 127: 325-332.

Gondwe, M., Krol, M., Gieskes, W.W.C., Klaassen, W., and de Baar, H.J.W. 2003. The contribution of ocean-derived DMS to the global atmospheric burdens of DMS, MSA, $\mathrm{SO}_{2}$ and $\mathrm{NSS}_{-} \mathrm{SO}_{4}{ }^{2-}$. Global Biogeochem. Cycles, 17: 1056 (doi: 10.1029/2002GB001937).

Haußecker, H., Reinelt, S., and Jähne, B. 1995. Heat as a proxy tracer for gas exchange measurements in the field: principle and technical realization. In Air-water gas transfer. Edited by B. Jähne and E.C. Monahan. Aeon, Hanau, Germany. pp. 405-413.

Hintsa, E.J., Dacey, J.W.H., McGillis, W.R., Edson, J.B., Zappa, C.J., and Zemmelink, H.J. 2004. Sea-to-air fluxes from measurements of the atmospheric gradient of dimethylsulfide and comparison with simultaneous relaxed eddy accumulation measurements. J. Geophys. Res. 109: C01026 (doi: 10.1029/2002JC001617).

Jacobs, C.M.J., Kohsiek, W., and Oost, W.A. 1999. Air-sea fluxes and transfer velocity of $\mathrm{CO}_{2}$ over the North Sea: results from ASGAMAGE. Tellus, 51: 629-641.

Jacobs, C., Kjeld, J.F., Nightingale, P., Upstill-Goddard, R., Larsen, S., and Oost, W. 2002. Possible errors in $\mathrm{CO}_{2}$ air-sea transfer velocity from deliberate tracer releases and eddy covariance measurements due to near-surface concentration gradients. J. Geophys. Res. 107 (doi: 10.1029/2001JC000983).

Jähne, B., Heinz, G., and Dietrich, W. 1987. Measurements of the diffusion coefficients of sparingly soluble gases in water. J. Geophys. Res. 92: 10767 - 10776.

Jähne, B., Libner, P., Fischer, R., Billen, T., and Plate, E.J. 1989. Investigating the transfer processes across the free aqueous viscous boundary layer by the controlled flux method. Tellus, 41: 177-195.

Jarvis, P.G., and McNaughton, K.G. 1986. Stomatal control of transpiration: scaling up from leaf to region. Adv. Ecol. Res. 15: $1-49$.

Jessup, A.T., Asher, W.E., Plant, W.J., McGillis, W.R., Zappa, C.J., Hintsa, E.H., Dacey, J.W.H., Farmer, D.M., Gemmrich, J., Vagle, S., Reising, S.C., and Zemmelink, H.J. 2002. The FAIRS experiment. IEEE Geosci. Remote Sens. Soc. Newsl. 123: 12-17.

Kettle, A.J., and Andreae, M.O. 2000. Flux of dimethylsulfide from the oceans: a comparison of updated data sets and flux models. J. Geophys. Res. 105: 26793 - 26808.

Kieber, D.J., Jianfu, J., Kiene, R.P., and Bates, T.S. 1996. Impact of dimethylsulfide photochemistry on methyl sulfur cycling in the equatorial Pacific Ocean. J. Geophys. Res. 101: 3715-3722.

Klaassen, W. 1992. Average fluxes from heterogeneous vegetated regions. Boundary Layer Meteorol. 58: 329-354.

Liss, P.S., and Merlivat, L. 1986. Air-sea gas exchange rates: introduction and synthesis. In The role of air-sea exchange in geochemical cycling. Edited by P. Buat-Ménard. D. Reidel, Boston, Mass. pp. 113-129.

Lovelock, J.E., Maggs, R.J., and Rasmussen, R.A. 1972. Atmospheric dimethyl sulfide and the natural sulfur cycle. Nature (Lond.), 237: 452-453.

McGillis, W.R., Dacey, J.W.H., Frew, N.M., Bock, E.J., and Nelson, R.K. 2000. Water-air flux of dimethylsulfide. J. Geophys. Res. 105: 1187-1193.

McGillis, W.R., Edson, J.B., Hare, J.E., and Fairall, C.W. $2001 a$. Direct covariance air-sea $\mathrm{CO}_{2}$ fluxes. J. Geophys. Res. 106: 16729 - 16745 .

McGillis, W.R., Edson, J.B., Ware, J.D., Dacey, J.W.H., Hare, J.E., Fairall, C.W., and Wanninkhof, R. 2001b. Carbon dioxide flux techniques performed during GasEx-98. Mar. Chem. 75: 267-280.

Mitchell, G.M. 2001. Determination of vertical fluxes of sulfur dioxide and dimethyl sulfide in the remote marine atmosphere by eddy correlation and an airborne isotopic dilution atmospheric pressure ionization mass spectrometer. Ph.D. thesis, Drexel University, Philadelphia, Pa.

Monin, A.S., and Obukhov, A.M.O. 1954. Fundamentale Gesetzmä Bigkeiten der turbulenten vermischung in der bodennahen schicht der atmosphäre. In Sammelband zur statistischen theory der turbulenz. Edited by $\mathrm{H}$. Goering. Deutsche Akademie der Wissenschaften zu Berlin, Berlin. pp. 199-226. 
Nightingale, P.D., Malin, G., Law, C.S., Watson, A.J., Liss, P.S., Liddicoat, M.I., Boutin, J., and Upstill-Goddard, R.C. 2000. In situ evaluation of air-sea gas exchange parameterizations using novel conservative and volatile tracers. Global Biogeochem. Cycles, 14: 373-387.

Oncley, S.P., Delany, A.C., Horst, T.W., and Tans, P.P. 1993. Verification of flux measurements using relaxed eddy accumulation. Atmos. Environ. Part A Gen. Top. 27: 2417-2426.

Pattey, E., Desjardins, R.L., and Rochette, P. 1993. Accuracy of the relaxed eddy-accumulation technique, evaluated using $\mathrm{CO}_{2}$ flux measurements. Boundary Layer Meteorol. 66: 341-355.

Paulson, C.A. 1970. The mathematical representation of wind speed and profile temperatures in the unstable atmospheric surface layer. J. Appl. Meteorol. 9: 857-861.

Putaud, J.P., and Nguyen, B.C. 1996. Assessment of dimethylsulfide sea-air exchange rate. J. Geophys. Res. 101: 4403-4411.

Rinne, H.J.I., Delany, A.C., Greenberg, J.P., and Guenther, A.B. 2000. A true eddy accumulation system for trace gas fluxes using disjunct eddy sampling method. J. Geophys. Res. 105: 24791 24798.

Rinne, H.J.I., Guenther, A.B., Warneke, C., de Gouw, J.A., and Luxembourg, S.L. 2001. Disjunct eddy covariance technique for trace gas flux measurements. Geophys. Res. Lett. 28: 3139-3142.

Saltzman, E.S., King, D.B., Holmen, K., and Leck, C. 1993. Experimental determination of the diffusion coefficient of dimethylsulfide in water. J. Geophys. Res. 98: 16481 - 16486.

Sciare, J., Mihalopoulos, N., and Dentener, F.J. 2000. Interannual variability of atmospheric dimethylsulfide in the southern Indian Ocean. J. Geophys. Res. 105: 26369 - 26377.

Smith, S.D., and Jones, E.P. 1986. Isotopic and micrometeorological ocean $\mathrm{CO}_{2}$ fluxes: different time and space scale. J. Geophys. Res. 91: 10529 - 10532 .

Spicer, C.W., Kenny, D.V., Chapman, E., Busness, K.M., and Berkowitz, C.M. 1996. Observations of dimethyl sulfide over the western North Atlantic Ocean using an airborne tandem mass spectrometer. J. Geophys. Res. 101: 29137 - 29147.

Wallace, D.W.R., and Wirick, C.D. 1992. Large air-sea gas fluxes associated with breaking waves. Nature (Lond.), 356: 694-696.

Wanninkhof, R. 1992. Relationship between wind speed and gas exchange over the ocean. J. Geophys. Res. 97: 7373-7382.

Wanninkhof, R., and McGillis, W.R. 1999. A cubic relationship between air-sea $\mathrm{CO}_{2}$ exchange and wind speed. Geophys. Res. Lett. 26: 1889-1892.

Watson, A.J., and Liss, P.S. 1998. Marine biological controls on climate via the carbon and sulphur geochemical cycles. Philos. Trans. R. Soc. Lond. B Biol. Sci. 353: 41-51.

Wesely, M.L., Cook, D.R., Hart, R.L., and Williams, R.M. 1982. Air-sea exchange of $\mathrm{CO}_{2}$ and evidence for enhanced upward fluxes. J. Geophys. Res. 87: 8827-8832.

Woolf, D.K. 1993. Bubbles and the air-sea transfer velocity of gases. Atmos. Ocean, 31: 517-540.

Wyngaard, J.C., and Moeng, C.H. 1992. Parameterizing turbulent diffusion through the joint probability density. Boundary Layer Meteorol. 60: 1-13.

Yvon, S.A., Saltzman, E.S., Bates, T.S., Cooper, D.J. 1996. Atmospheric sulfur cycling in the tropical Pacific marine boundary layer $\left(12^{\circ} \mathrm{S}, 135^{\circ} \mathrm{W}\right)$ : a comparison of field data and model results. 1. Dimethylsulfide. J. Geophys. Res. 101: 6899-6910.

Zemmelink, H.J., Gieskes, W.W.C., Klaassen, W., Beukema, W.J., de Groot, H.W., de Baar, H.J.W., Hintsa, E.J., McGillis, W.R., and Dacey, J.W.H. 2004a. Relaxed eddy accumulation measurements of the sea-to-air transfer of dimethylsulfide over the northeastern Pacific. J. Geophys. Res. 109: C01025 (doi: 10.1029/2002JC001616).

Zemmelink, H.J., Gieskes, W.W.C., Klaassen, W., de Groot, H.W., de Baar, H.J.W., Dacey, J.W.H., Hintsa, E.J., and McGillis, W.R. 2004b. Air-sea gas transfer rates derived from atmospheric dimethyl sulphide fluxes. J. Geophys. Res. In press. 